ISSN: 0377-6395
e-ISSN: 2651-4214
DETERINER HEKIMLER DERNEĞI

doi: 10.33188/vetheder.470873

Araştırma Makalesi / Research Article

\title{
Akut solunum güçlüğü sendromu bulunan 84 kedide klinikopatolojik bulguların değerlendirilmesi
}

\author{
Hadi ALIHOSSEINI ${ }^{a^{*}}$, Ekrem Çağatay ÇOLAKO $\breve{G L U}$ \\ ${ }^{a}$ Terapist Veteriner Tip Merkezi, İstanbul, Türkiye \\ ${ }^{b}$ Ankara Üniversitesi Veteriner Fakültesi, İç Hastalıkları Anabilim Dalı, Dışkapı, Ankara, Türkiye
}

\author{
MAKALE BILGISI: \\ ARTICLE \\ INFORMATION: \\ Geliş / Received: \\ 15 Ekim 18 \\ 15 October 18 \\ Kabul / Accepted: \\ 04 Aralık 18 \\ 04 December 18
}

Anahtar Sözcükler:

Akciğer

Dispne

Kalp

Kedi

Solunum

Keywords:

Cat

Dyspnea

Heart

Lung

Respiratoy
ÖZET:

Akut solunum güçlüğü sendromu (ARDS) kedilerde acil müdahale gerektiren ve mortalitesi oldukça yüksek bir klinik sendromdur. Dokuların yeterli düzeyde oksijenlenmesindeki sorunlar şiddetli fiziksel ve mental disstrese neden olmakta ve bu durum hızlı şekilde ölüm ile sonuçlanabilmektedir. Bu çalışma; ARDS'li kedilerde klinikopatolojik bulguların değerlendirilmesini amaçlamaktadır. Çalıșma akut solunum güçlüğü ve taşipne şikayeti ile getirilen 84 kedi ile gerçekleştirildi. Eşgal ve anamnez bilgileri kaydedilen hastalarda vücut 1sısı, kapillar dolum zamanı, dakikadaki solunum sayısı ve dehidrasyon derecesi belirlendi; mukoza kontrolleri, kalp ve akciğer oskültasyonları kısa sürede yapıldı. Ayırıcı tanıya gidebilmek için hastalarda kan analizleri ve diyagnostik uygulamalar gerçekleştirildi. Çalışmaya dahil edilen kedilerin (n:84) 55'i acil vaka olarak değerlendirildi ve oksijen desteği sağlandı. Hastaların 71' inde kan analizleri, 68'inde toraks grafileri, 22'sinde Ekokardiyografi ve 3' ünde torakosentez uygulandı. Çalışmada; solunum güçlügü olan 84 kedinin 65 'inde (\%77.38) non-kardiyojenik nedenler, 19 kedide ise (\%22.62) kardiyojenik nedenler belirlendi. Sonuç olarak; kedilerde akut respiratorik disstres sendromu bir çok klinikopatolojik nedene bağlı şekillenmekte ve hızlı tanı ve tedavi yapılmazsa akut solunum aresti sonucu ölüme neden olmaktadır.

\section{Evaluation of clinicopathologic characteristics in 84 cats with acute respiratory distress syndrome}

ABSTRACT:

Acute respiratory distress syndrome (ARDS) characterized by high mortality in cats has a requirement of emergency care. Problems in tissue oxygenation cause physical and mental distress resulting in acute death. The purpose of the study presented here was to evaluate clinicopathologic characteristics in cats with ARDS. Study was performed in 84 cats with acute respiratory distress and tachypnea. Capillary refill time, respiratory rate, dehydration, mucosal color, heart and lung auscultation with the signalment and anamnesis were also provided immediately. Blood analyses and diagnostic applications were performed for differential diagnosis. Of cats enrolled into the study (n:84), 55 was defined as emergency cases and supported by supplemental oxygenation. Blood analyses in 71 cats, thorax graphies in 68 cats, echocardiography in 22 cats and thoracocentesis in 3 cats were applied. Of 84 cats with dyspnea, in 65 (77.38\%) noncardiogenic etiologies, in $19(22.62 \%)$ cardiogenic reasons were determined. In conclusion, acute respiratory distress syndrome would result from lots of clinicopathologic etiologies and cause acute respiratory arrest until fast diagnosis and therapy supplied.

\footnotetext{
* Sorumlu yazar / Corresponding author

e-posta adresi / e-mail address: hadi.alihosseini@gmail.com
} 


\section{Giriş}

Akut solunum güçlüğü sendromu (ARDS) kedilerde acil müdahale gerektiren, tedavisi güç olan ve mortalitesi yüksek bir klinik sendromdur. Dokuların yeterli düzeyde oksijenlenmesindeki sorunlar şiddetli fiziksel ve mental disstrese neden olmakta ve bu durum hızlı şekilde ölüm ile sonuçlanabilmektedir. Erken klinik bulguların tespiti hasta sahipleri için zor olabilirken, şiddetli bulgular oldukça tehlikeli sonuçlar doğurabilmektedir $(9,21)$. Nazal boşluktan plöral boşluğa kadar solumum sistemini etkileyen her etki potansiyel olarak solunum güçlüğüne neden olabilir (6). Ölüm oranı yüksek olan bu sendromda olası etiyolojik nedenler olarak; üst-alt solunum yolu hastalıkları, plöral hastalıklar, mediastinal hastalıklar, toraks içi ve toraks dışı travmalar, kalp yetmezliği ve neoplastik hastalıklar sayılabilmektedir $(15,21)$. Stres bu hastalar için öldürücü olabildiğinden nedeni ortaya koymaya yönelik uygulamalar mutlaka hastalar stabilize edildikten sonra sürdürülmelidir (23).

Solunum güçlüğü gösteren 106 kedi ile yapılan bir çalışmada; kedilerin \% 57.5'sinde hipertrofik kardiyomiyopati, \% 20.7'sinde restriktif kardiyomiyopati, \%10.4 dilate kardiyomiyopati ve \% 10.4 klasifiye edilmemiş kardiyomiyopati bildirilmiştir (7). Atrial ve ventriküler septal defekt gibi doğmasal kalp hastalıkları ise özellikle yavru kedilerde ani başlayan nefes darlığı ve dispnenin nedeni olabilir (13).

Dispne belirtileri taşıyan kedilerde; trahea ve larenks tümörleri ve lenfosarkom olası nedenler olarak dikkat çekmektedir (1). Bu tür kedilerde ayrıca; plöral efüzyon, kedilerin enfeksiyöz peritonitisi, aelurostrongilus enfestasyonu, mediastinal lemfoma, diyaframatik herni, kosta kırıkları, pnömotoraks, şilotoraks ve piyotoraks da diğer olası solunum güçlüğü nedenleri arasındadır $(5,11,14,20)$. İdiyopatik pulmoner fibrozis ise kedilerde solunum disstresine neden olan ve çoğunlukla dispne ile sonuçlanan ilerleyici yangısal olmayan interstisyel akciğer hastalığıdır (25). Pektus ekskavatum gibi doğmasal göğüs kafesi anomalileri de yavru kedilerde giderek ilerleyen dispneye neden olabilmektedir (3).

ARDS'li kedilerde klinikopatolojik bulguların yeterince değerlendirilmemesi; ilerleyici solunum güçlüğünün hipoksi ile sonuçlanmasına, ventilasyon anormalliklerine, asit baz dengesi bozukluklarına ve sonunda da solunum arestine neden olmaktadır. $\mathrm{Bu}$ çalışma ile; ARDS semptomu gösteren kedilerde klinikopatolojik bulguların değerlendirilmesi amaçlanmaktadır.

\section{Gereç ve Yöntem}

Çalışma Ankara Üniversitesi Veteriner Fakültesi Hayvan Hastanesi ve Terapist Veteriner Tıp Merkezi’ne akut solunum güçlüğü (açık ağız solunum, gürültülü solunum, boyun ve başı ileriye doğru uzatma) ve hızlı solunum (taşipne) şikayeti $(9,23)$ ile getirilen çeşitli yaş, 1rk ve cinsiyetteki 84 kedi ile gerçekleştirildi. Tüm hastalara entübasyon, maske ya da çadır yöntemi ile öncelikle oksijen desteği sağlandı ve kardiyopulmoner monitorizasyonları yapıldı. Anksiyetik kedilerde Butorfanol $0.1 \mathrm{mg} / \mathrm{kg}$ dozunda deri altı uygulandı. Eşgal ve anamnez bilgileri kaydedilen hastalarda vücut 1S1s1, kapillar dolum zaman1, dakikadaki solunum sayıs1 ve dehidrasyon derecesi belirlendi; mukoza kontrolleri, kalp ve akciğer oskültasyonları kısa sürede $(<2 \mathrm{dk})$ yapıldı. Ayırıcı tanıya gidebilmek için hastalarda tam kan analizleri (WBC, LYM, MON, NEUT, EOS, LYM\%, MON\%, NEUT\%, EOS\%, RBC, HGB, HCT, MCV, MCH, MCHC, RDWa, RDW\%, PLT, MPV), bazı serum biyokimyasal parameterleri, toraks grafileri ve ekokardiyografik muayeneler yapıldı. Toraks grafileri, hastalardaki solunum güçlüğü şiddetleri gözönüne alınarak yalnızca laterolateral veya yalnızca dorsoventral pozisyonda alındı. Plöral ya da perikardial efüzyonu bulunan hastalarda diyagnostik ya da terapatik torakosentez uygulandı. Çalı̧̧maya dahil edilen tüm hastalara uygun tedavi desteği sağlandı. 


\section{İstatistik analizler}

Elde edilen tüm parametrelere ait tanımlayıcı istatistikler hesaplandı ve sürekli veriler için Aritmetik Ortalama \pm Standart Hata; kategorik veriler için ise yüzdeler (\%) halinde gösterildi. Verilerin değerlendirilmesi için SPSS 14.01 paket programindan faydalanıldı.

\section{Bulgular}

Çalışmaya dahil edilen kedilerin (n:84) 55'i acil vaka olarak değerlendirildi ve oksijen desteği sağlandı. Acil tıbbi gereksinimi olan kediler sirasıyla Kırma (n:33), Siyam (n:8), İran (n:7), Ankara (n:5) ve Van (n:2) 1rk1 kedilerden oluştu. Tüm hastaların ayrıntılı eşgal bilgileri Tablo 1'de gösterildi.

Tablo 1: Çalışmaya dahil edilen kedilerin (n:84) eşgal bilgileri.

Table 1: Signalment of the cats (n:84) enrolled the study.

\begin{tabular}{|c|c|c|c|c|c|c|}
\hline \multirow{2}{*}{$\mathrm{CA}(\mathrm{Kg})$} & \multirow{2}{*}{ Yaş (Ay) } & \multirow[t]{2}{*}{ Irk $(\mathrm{n}, \%)$} & \multicolumn{2}{|c|}{ Cinsiyet } & \multicolumn{2}{|c|}{ Reprodüktif Durum } \\
\hline & & & $\hat{0}$ & q & Kısırlaştırılmış & Kısırlaştırılmamış \\
\hline $3,77 \pm 0,15$ & $59,6 \pm 13,02$ & $\begin{array}{c}\text { Kırma Irk } \\
(39, \% 46,42), \\
\text { Siyam kedisi } \\
(12, \% 14,3), \\
\text { İran Kedisi } \\
(9, \% 10,8), \\
\text { Ankara Kedisi } \\
(8, \% 9,52), \\
\text { British Shorthair } \\
\text { (7, \%8,3), } \\
\text { Van Kedisi } \\
(5, \% 5,95), \\
\text { Şinşila } \\
(4, \% 4,7)\end{array}$ & $\begin{array}{c}40 \\
(\% 47,61)\end{array}$ & $\begin{array}{c}44 \\
(\% 52,38)\end{array}$ & $61(\% 72,61)$ & $23(\% 27,39)$ \\
\hline
\end{tabular}

Hastaların 71' inde kan analizleri (43'ünde tam kan, 28'inde tam kan ve serum biyokimyası birlikte), 68'inde toraks grafileri, 22'sinde Ekokardiyografi ve 3' ünde torakosentez uygulandı. Kedilerin klinik muayene bulguları Tablo 2'de gösterildi.

En sık dikkati çeken klinik muayene bulguları sırasıyla; Açık A ğız solunum (n:62, \% 73,8), taşipne (n:22, \% 26,2), gürültülü solunum (n:6, \% 7,14) ve başı ileriye doğru uzatma (n:3, \% 3.6) olarak belirlendi.

Çalışmada; solunum güçlüğü olan 84 kedinin 65 'inde $(\% 77,38)$ non-kardiyojenik nedenler, 19 kedide ise $(\% 22,62)$ kardiyojenik nedenler belirlendi (Tablo 3). 
Tablo 2: Çalışmaya dahil edilen kedilerin (n:84) klinik muayene bulguları.

Table 2: Clinical signs of cats (n:84) enrolled the study.

\begin{tabular}{lc}
\hline Klinik Muayene Bulguları* & $\mathbf{n} ; \%$ \\
\hline Vücut Islsl $\left(C^{\circ}\right)$ & \\
$\quad<37$ & $18 ; 21,5$ \\
$37-39,3$ & $52 ; 61,9$ \\
$>39,3$ & $14 ; 16,6$ \\
Kapillar Dolum Zamanı (sn) & \\
$\quad<2$ & $68 ; 80,9$ \\
$>2$ & $16 ; 19,1$ \\
Dehidrasyon Derecesi (\%) & \\
$<5$ & $59 ; 70,2$ \\
$5-7$ & $18 ; 21,4$ \\
$>7-9$ & $7 ; 8,3$ \\
Mukozal Renk & \\
Siyanotik & $4 ; 4,76$ \\
Solgun & $6 ; 7,14$ \\
Normal & $74 ; 88,09$ \\
\hline
\end{tabular}

*Kalp Atım Sayısı/dk: $214 \pm$ 9, 2; Solunum Sayısı/dk: 42 $\pm 4,6$

Tablo 3: Çalışmaya dahil edilen kedilerde (n:84) solunum güçlüğünün nedenleri.

Table 3: Causes of respiratory distress in cats (n:84) enrolled the study.

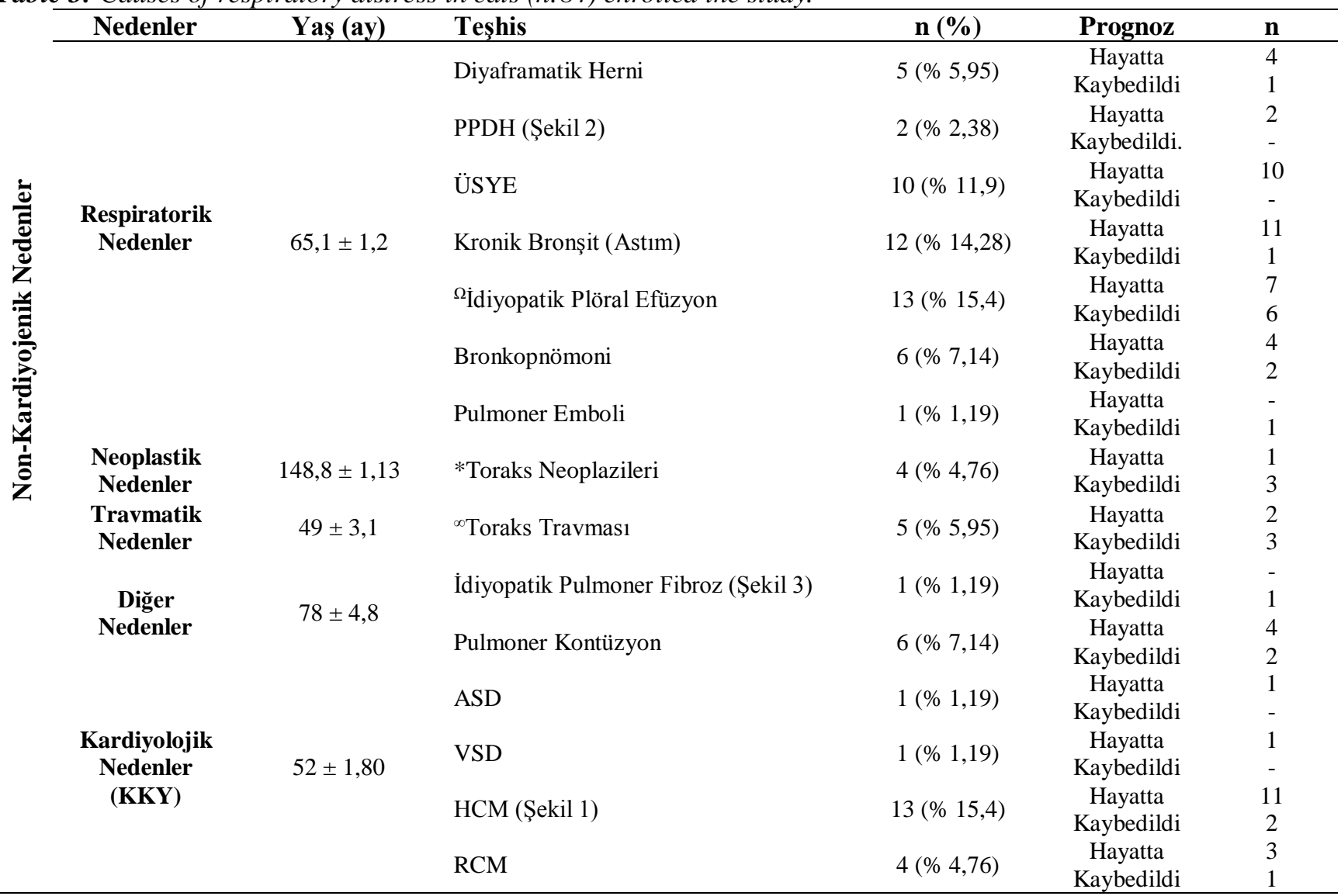

ÜSYE: Üst Solunum Yolu Enfeksiyonu, ASD: Atrial Septal Defekt, VSD: Ventriküler Septal Defekt, HCM: Hipertrofik Kardiyomyopati, RCM: Restriktif Kardiyomyopati, KKY: Konjestif Kalp Yetmezliği, PPDH: Peritoneoperikardial divaframatik herni. ${ }^{\Omega}$ Plöral efüzyonlu tüm kediler kedilerin enfeksiyöz. peritonitisi yönünden negatifti (Idexx FIP Ab), *3 hastada metastatik akciğer karsinomu, 1 hastada mediastinal lenfoma belirlendi. ${ }^{\infty}$ Trafik kazaları, isirlk yaralarl ve toraks yabancl cisimleri 


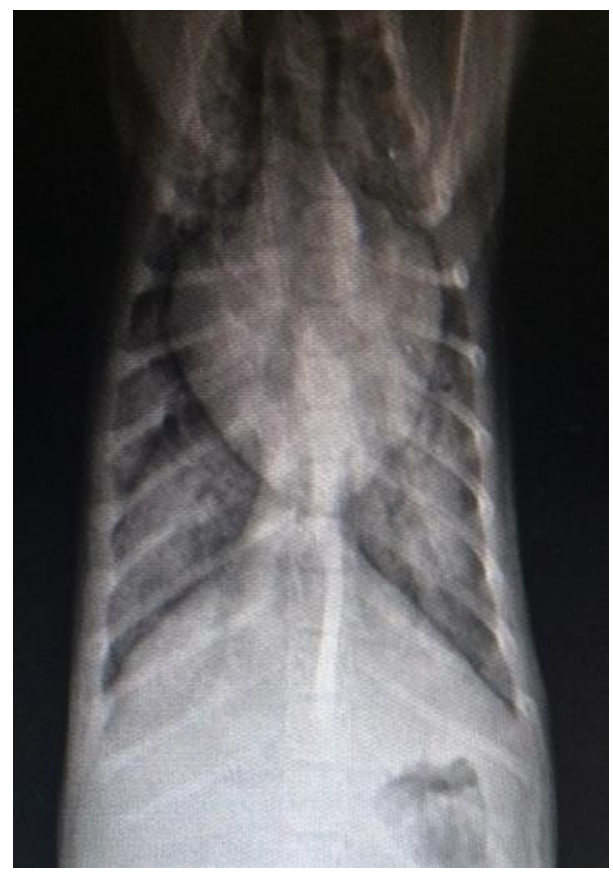

Şekil 1: Hipertrofik kardiyomiyopatisi olan 5 yaşındaki bir kedide akciğer ödemi ve kardiyomegali.

Figure 1: Pulmonary edema and cardiomegaly in a 5 year old cat with hypertrophic cardiomyopathy.
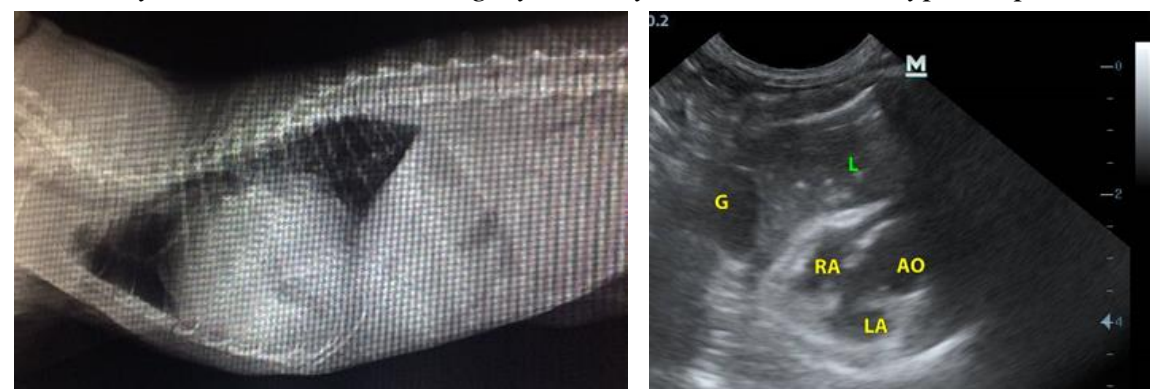

Şekil 2: Ani şekillenen dispnesi olan British shorthair ırkı bir kedide peritoneoperikardial herninin radyografik (a) ve ekokardiyografik (b) görünümü. AO: Aort, LA: Sol Atrium, RA: Sağ atrium.

Figure 2: Radiographic (a) and echocardiographic (b) view of peritoneal-pericardial hernia in a British shorthair cat with acute dyspnea. AO: Aorta, LA: Left atrium, RA: Right atrium

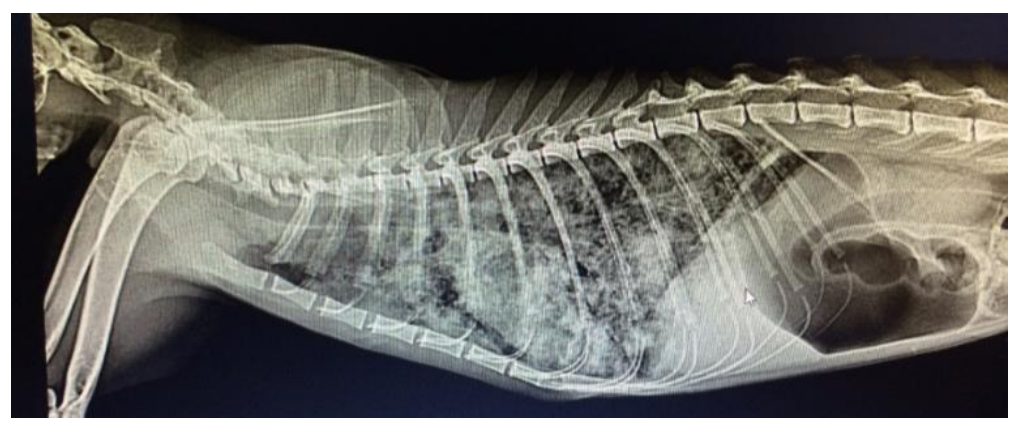

Şekil 3: 6 yaşlı dispneli bir kedide idiyopatik pulmoner fibroz.

Figure 3: Idiopathic pulmonary fibrosis in a 6 year-old cat with dyspnea. 


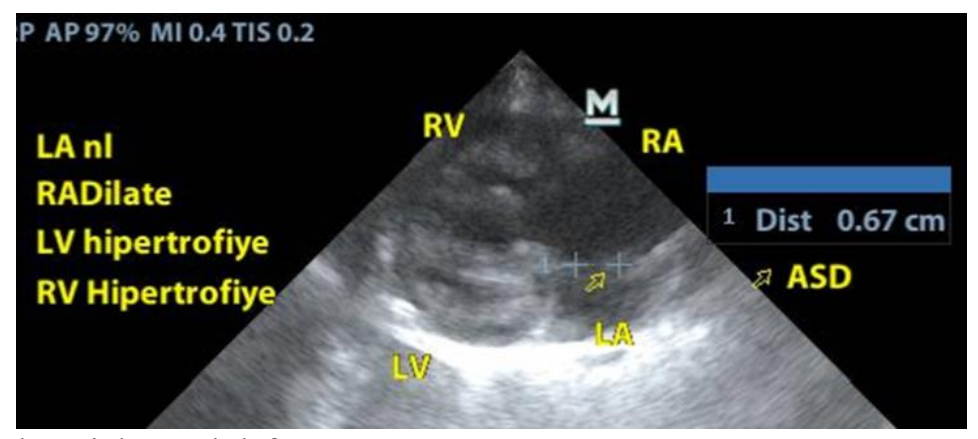

Şekil 4: Bir İran kedisinde atrial septal defect (ASD). LA: Sol atrium, LV: Sol ventrikül, RA: Sağ atrium, RV: Sağ ventrikül.

Figure 4: Atrial septal defect (ASD) in a Persian cat. LA: Left atrium, LV: Left ventricule, RA: Right atrium, RV: Right ventricule.

\section{Tartışma ve Sonuç}

Yüksek mortalite oranlarıyla karakterize ARDS; üst ve alt solunum yolları hastalıkları, plöral hastalıklar, mediastinal problemler, toraks travmaları, kalp yetmezliği ve neoplastik hastalıkları gibi nedenlerle şekillenebilmektedir (18). Özellikle İran ve himalayan ırkı kediler gibi brahisefalik ırklarda stenotik burun deliklerinin varlığı, solunum yolu enfeksiyonları, nazal tümörler ve larengeal paralizi kapsayan üst solunum yolu hastalıkları dispne ile sonuçlanmaktadır $(8,18)$. Alt solunum yolu hastalıkları (bronkopnömoni, pulmoner ödem, tromboembolizm ve neoplazi) ve kedi astımı ise hastalığın ileri aşamalarında ciddi solunum yetmezliğine neden olabilmektedir $(4,19)$. Bu çalışmada da; literatür verileriyle uyumlu şekilde üst ve alt solunum yolu hastalıklarını kapsayan bir çok respiratorik neden tanımlanmıştır.

Oksijen tedavisine direnç gösteren dispneli kedilerde pulmoner tromboembolizmden şüphelenilmesini gerektiği bildiren literatür verileri rapor edilmektedir (19). Bu çalışmada da 84 kedinin 65 'inde (\% 77.4) nefes darlığ non-kardiyojenik nedenlerden kaynaklanmış bir kedide ise pulmoner tromboembolizm belirlenmiştir. Pulmoner tromboembolizm belirlenen hasta trombolitik tedaviye yanıt vermiştir.

Ruiz et al (17) çalışmasında konjestif kalp yetmezliğinin kedilerde plöral efüzyon ve dispnenin en önemli nedeni olduğu bildirilmektedir. Diğer olası dispne nedenleri olarak; neoplazi, pyotoraks, şilotoraks, travma, kedilerin enfeksiyöz peritonitisi ve diyaframatik herni rapor edilmiştir. Sunulan çalışmada da; Ruiz et al (17) verilerine benzer şekilde dispneli kedilerde konjestif kalp yetmezliği nedenleri olarak septal defekt ve kardiyomyopati tanıları ekokardiyografik olarak belirlenmiştir. Konjenital kalp hastalıkları, hipertrofik kardiyomiyopati, restriktif kardiyomiyopati ve aritmojenik sağ ventrikül kardiyomyopati gibi kardiyolojik hastalıklar kedilerde solunum yetmezliğine yol açmaktadır (7). Kalp hastalıklarında dispnenin nedeni pulmoner ödem ve plöral efüzyon olabilmektedir. Bu çalışmada da 84 dispneli kedinin 17'sinde (\%20.2) kardiyomiyopati nedenli pulmoner ödem ve dispne belirlenmiştir. Plöral efüzyonlu hiçbir kedide enfeksiyöz peritonitis tanısı doğrulanamamıştır.

Lenfoma, timoma ve akciğer karsinomları solunum yetmezliği ile sonuçlanan neoplastik durumlardır $(2,8$, 16). Sunulan çalışmada da mediastinal lenfoma ve akciğer neoplazileri nedenli dispneli vakalar tespit edilmiştir. Toraks travmaları kedilerde ani solunum yetmezliği ve nefes darlığına yol açan acil durumlardandır. Trafik kazaları, yabancı cisim batmaları, yüksekten düşme, pnömotoraks ve toraks travmalarına bağlı oluşan pulmoner kontüzyonlar acil müdahale gerektirmektedir. $\mathrm{Bu}$ hastaların muayene ve uzun süreli manipülasyonları istenmeyen durumlarla sonuçlanabilmektedir (12). Dispnesi olan hastalarda radyografik muayene ile hızlıca tanının konulması ve tanısal manipülasyonların en aza indirilmesi gerekmektedir (10). Yapılan bir çalışmada yükseten düşen ve göğüs travması oluşan 132 kedinin \% 8'inde pulmoner kontüzyon ve \% 63'ünde pnöumotoraks kaydedilmiştir (24). Bu araştırmada hastaların büyük kısımında klinik olarak belirgin solunum güçlüğü saptanmıştır. Sunulan çalışmada; 84 kedinin 6'ında 
(\%7.14) pulmoner kontüzyon, 5 'inde de (\% 5.95) toraks travması (trafik kazaları, 1sırık yaralar1 ve yabanc1 cisim batma) radyografik olarak saptanmıştır.

Kedi astımı tekrarlayan öksürük ve dispne ile karakterize klinik bir durumdur. Hastalık, kedilerin efor sonrası tıkanmaları ve ani solunum güçlügü ile karakterizedir (4). Bu çalışmada 84 kediden 12 'inde (\%14.28) kedi astımı (kronik bronşit) tanısı konulmuştur.

Konjenital olarak görülen PPDH ileri yaşlarda asemptomatik olarak seyredebilmektedir. Bu hastalarda ani başlayan solunum güçlüğü genelde altta yatan toraks travmalarına bağlıdır (22). Sunulan çalışmada da 2 kedide (\%2.38) PPDH saptanmıştır.

Sepsis köpeklerde olduğu gibi kedilerle yapılan çalışmalarda da ARDS'nin önemli bir sekeli olarak tanımlanmaktadır (9). Sunulan çalışmada her ne kadar ayırıcı tanı amacıyla kan analizleri gerçekleştirilmiş olsa da, bu analizlerde sepsis göstergelerinin istatistiki değerlendirilmesinin yapılmaması sepsisin ARDS'li kedilerdeki olası etkilerinin ortaya konulmasını engellemiştir. Sepsisli hastalar da diğer hastalar gibi uygun yöntemlerle sağaltılmışlardır.

Sonuç olarak; kedilerin ARDS sendromu bir çok klinikopatolojik nedene bağlı şekillenmekte ve hızlı tanı ve tedavi yapılmazsa akut solunum aresti sonucu ölüme neden olmaktadır.

\section{Kaynaklar}

1. Carlisle CH, Biery DN, Thrall DE (1991): Tracheal and laryngeal tumors in the dog and cat: literature review and 13 additional patients. J Vet Radiol Ultrasound, 32 (5), 229-23.

2. Cervone M, Beurlet S (2016): Primary bronchial carcinoma associated with bone marrow metastasis and paraneoplastic monoclonal gammopathy in a cat. JFMS, 2(2), 1-5.

3. Charlesworth T (2017): Pectus excavatum: congenital thoracic deformity in cats. In Practice, 39(2), 73-78.

4. Corcoran BM, Foster DJ, Fuentes VL (1995): Feline asthma syndrome: a retrospective study of the clinical presentation in 29 cats. J Small Anim Pract, 36(11), 481-8.

5. Davies C, Forrester SD (1996): Pleural effusion in cats: 82 cases (1987 to 1995). J Small Anim Pract, 37(5), 21724.

6. Felix N (2012): Management of patients with respiratory distress. Proceedings of the international congress of the Italian association of companion animal veterinarians.

7. Ferasin L, Sturgess CP, Cannon MJ, Caney SM, Gruffydd-Jones TJ, Wotton PR (2003): Feline idiopathic cardiomyopathy: a retrospective study of 106 cats (1994-2001). J Feline Med Surg, 5(3), 151-9.

8. Jakubiak MJ, Siedlecki CT, Zenger E, Matteucci ML, Bruskiewicz KA, Rohn DA, Bergman PJ (2005): Laryngeal, laryngotracheal, and tracheal masses in cats: 27 cases (1998-2003). J Am Anim Hosp Assoc, 41(5), 3106.

9. Kornya M (2016). Acute respiratoy distress syndrome and acute lung injury in cats. Erişim: https://www.winnfelinefoundation.org/docs/default-source/cat-health-library-educational-articles/acute-respiratorydistress-syndrome.pdf?sfvrsn=2. Erişim tarihi: 12.10 .2018 .

10.Kraje BJ, Kraje AC, Rohrbach BW, Anderson KA, Marks SL, Macintire DK (2000): Intrathoracic and concurrent orthopedic injury associated with traumatic rib fracture in cats: 75 cases (1980-1998). J Am Vet Med Assoc, 216 (1), 51-4.

11.Luis Fuentes V (1998): Differential diagnosis of dyspnoea. 123-128 In: Luis Fuentes V, Swift S (Eds.), Manual of Small Animal Cardiorespiratory Medicine and Surgery. BSAVA, Gloucester, UK.

12. Lux CN, Culp WT, Mellema MS, Rosselli DD, Schmiedt CW, Singh A, Mayhew PD (2018): Factors associated with survival to hospital discharge for cats treated surgically for thoracic trauma. JAVMA, 253(5), 598-605.

13. MacDonald KA (2006): Congenital heart diseases of puppies and kittens. Vet Clin No Am Sm An Prac, 36, 503531. 
14. Martin M, Corcoran B (2006): Cough, dyspnea and tachypnoea. 86-91 In: Martin M, Corcoran B (Eds.), Notes on Cardiorespiratory Diseases of Dogs and Cats. 2nd edn. Blackwell Publishing, Oxford, UK.

15. Olsen D, Renberg W, Perrett J, Hauptman JG, Waldron DR, Monnet E (2002): Clinical management of flail chest in dogs and cats: a retrospective study of 24 cases (1989-1999). J Am Anim Hosp Assoc, 38(4), 315-20.

16. Patnaik AK, Lieberman PH, Erlandson RA, Antonescu C (2003) Feline cystic thymoma: a clinicopathologic, immunohistologic, and electron microscopic study of 14 cases. J Feline Med Surg, 5(1), 27-35.

17. Ruiz MD, Vessières F, Ragetly GR, Hernandez JL (2018): Characterization of and factors associated with causes of pleural effusion in cats. J Am Vet Med Assoc, 253(2), 181-187.

18. Schachter S, Norris CR. (2000): Laryngeal paralysis in cats: 16 cases (1990-1999). J Am Vet Med Assoc, 216(7), 1100-3.

19. Schermerhorn T, Pembleton-Corbett JR, Kornreich B (2004): Pulmonary thromboembolism in cats. J Vet Intern Med, 18(4), 533-5.

20. Schmiedt CW, Tobias KM, Stevenson MA (2003): Traumatic diaphragmatic hernia in cats: 34 cases (19912001). J Am Vet Med Assoc, 1(9), 1237-40.

21.Swift S, Dukes-McEwan J, Fonfara S, Loureiro JF, Burrow R (2009): Aetiology and outcome in 90 cats presenting with dyspnoea in a referral population. J Small Anim Pract, 50(9), 466-73.

22.Sydney M, Biery DN (1980): Congenital peritoneopericardial diaphragmatic hernia in the dog and cat: a literature review and 17 additional case histories. J vet Radiol Ultrasound, (21)3, 108-116.

23. Tseng LW, Waddell LS (2000): Approach to the patient in respiratory distress. Clin Tech Sm An Pract, 15, 5362.

24. Whitney WO, Mehlhaff CJ (1987): High-rise syndrome in cats. J Am Vet Med Assoc, 191(11), 1399-403.

25. Williams K, Malarkey D, Cohn L, Patrick D, Dye J, Toews G (2004): Identification of spontaneous feline idiopathic pulmonary fibrosis: morphology and ultrastructural evidence for a type II pneumocyte defect. Chest, 125(6), 2278-88. 